\title{
Las competencias clínicas
}

\author{
Jesús Millán Nuñez-Cortés \\ Catedrático de Medicina. Hospital General Universitario Gregorio Marañón, \\ Facultad de Medicina, Universidad Complutense
}

Las nuevas tendencias en educación médica nos permiten vislumbrar un panorama educativo en el que van a adquirir protagonismo aspectos relacionados con los estándares de calidad de la enseñanza, con nuevas metodologías educativas, o con los avances en la evaluación del conocimiento y de las competencias adquiridas.

En este sentido es preciso hacer énfasis en la definición de las competencias que estimamos que deberían alcanzar los alumnos, así como en los métodos para evaluarlas. No es fácil dar una respuesta uniforme a la definición de competencias. No obstante será preciso realizar un esfuerzo al objeto de definir bien aquello que entendemos que todos los alumnos deben conocer y saber hacer a su paso por las Facultades de medicina.

En efecto, será preciso definir bien aquello para lo que el alumno debe alcanzar competencia profesional. En el mundo de la educación médica tan importante es conocer lo que se tiene que hacer, cómo conocer cómo se tiene que hacer, y por quien ha de ser hecho. Desafortunadamente tenemos amplia experiencia en la que se demuestra que participar en las diferentes actividades o proyectar mejoras en las actividades prácticas clínicas no es sinónimo de adquirir una cierta competencia clínica. En este sentido cobra especial trascendencia la definición de las competencias clínicas que el alumno debe alcanzar, y ello debe servir de guía tanto para el alumno como para el profesor.

Se trata, en suma, de armonizar los conocimientos con las habilidades y con las actitudes para llegar a ser habilitado y reconocido como un buen profesional. Sólo el que ha adquirido las competencias clínicas apropiadas junto a los conocimientos precisos pueden ser considerados profesionales capacitados para ejercer su profesión. Y este es un criterio de calidad tanto para los centros de enseñanza (facultades) como para la propia sociedad que exige un profesional competente.

\section{LA DEFINICIÓN DE LAS COMPETENCIAS}

En las Facultades de Medicina, aproximadamente una tercera parte de las competencias que el alumno debe alcanzar se han de relacionar con la posibilidad de realizar una correcta historia clínica y exploración clínica estableciendo también una correcta comunicación con el enfermo y/o sus familiares. Se trata, por tanto, de adquirir un método clínico, propio del acto médico, con el que el alumno pueda combinar sus conocimientos teóricos. Otra tercera parte de las competencias que deberían alcanzar se relacionan, precisamente, con la capacidad de integrar los conocimientos teóricos para realizar el trabajo intelectual de emitir un juicio clínico, con una aproximación diagnóstica, un diagnóstico diferencial, una evaluación pronóstica (al menos teórica) y una estrategia terapéutica. El tercio restante de competencias podría, en la práctica, englobar a todas las demás competencias que los alumnos deberían alcanzar en sus estudios de medicina.

Por lo tanto, parece muy apropiada la aproximación de la Conferencia de Decanos de Facultades de Medicina, en la que se definen competencias en el ámbito del "saber" (conocimiento puro, o aspectos de diagnóstico y manejo de los problemas médicos), y en el ámbito del "saber hacer" (ya sea porque lo haya visto realizar, lo haya realizado de forma tutelada, o deba ser capaz de hacerlo de forma autónoma). Este enfoque es, asimismo, compatible con las líneas estratégicas planteadas por la Sociedad Española de Educación Médica, y que no son otras que:

- Definición del producto a formar

- Definición de las competencias

- Definición del modelo curricular

- La estructura y composición del currículo

- La gestión del programa educativo

- La evaluación

- Los recursos humanos y materiales

En el ya citado trabajo-propuesta de la Conferencia de Decanos de las Facultades de Medicina, el bloque correspondiente a "Patología Humana" representa más del 50\% de las competencias que el alumno debería alcanzar. Este "protagonismo" de las competencias clínicas se encuentra plenamente justificado si consideramos lo que ha de exigirse a un futuro médico. 


\section{EVALUACIÓN DE HABILIDADES Y PROCEDIMIENTOS CLÍNICOS}

Parece claro que las prácticas clínicas cada vez son mejores y más abundantes pero que este fenómeno no se acompaña de forma definitiva de una mejora en la adquisición de las competencias clínicas del alumno. Probablemente este hecho se debe a factores de origen muy diverso, pero entre los que sería preciso señalar la inexistencia de objetivos concretos y de definición previa de las competencias que se deben alcanzar.

De una encuesta realizada por nosotros a los alumnos de prácticas de clínica médica cabe desprender que el "modelo" de prácticas (que debe ser bastante generalizado) es el siguiente:

- Paso por una media de dos unidades clínicas/año

- Periodos de prácticas en la zona de

hospitalización (100\%), y con menor frecuencia

en unidades de exploraciones especiales, consultas o urgencias

- Las dos terceras partes de su tiempo se encuentran acompañados, y la tercera parte realizan actividades "en solitario"

- Las actividades que realizan más $\mathrm{f}$

recuentemente se muestran en la tabla 1.

TABLA 1. Perfil de las prácticas de clínica médica

(\% de alumnos) (encuesta personal)

\begin{tabular}{|c|c|c|}
\hline Actividad realizada & Muy Frecuente & Nunca \\
\hline Comentarios sobre Historia Clínica & $45,2 \%$ & $0 \%$ \\
\hline Realización de Historia Clínica & $9,8 \%$ & $1,6 \%$ \\
\hline \multicolumn{3}{|l|}{ Comentarios sobre } \\
\hline Exploración Clínica & $19,4 \%$ & $0 \%$ \\
\hline Realización Exploración Clínica & $14,5 \%$ & $3,2 \%$ \\
\hline \multicolumn{3}{|l|}{ Comentarios sobre exploración } \\
\hline complementaria & $12,9 \%$ & $3,2 \%$ \\
\hline \multicolumn{3}{|l|}{ Realización de exploración } \\
\hline complementaria & $1,6 \%$ & $64,5 \%$ \\
\hline \multicolumn{3}{|l|}{ Comentarios sobre } \\
\hline evolución y seguimiento & $9,4 \%$ & $3,2 \%$ \\
\hline
\end{tabular}

Asimismo, nos ha interesado conocer qué tipo y en qué grado los alumnos consideran que han alcanzado determinadas competencias. A este respecto se ha realizado una autoevaluación de los alumnos sobre la base de un cuestionario previamente utilizado en las Facultades de Barcelona y de Córdoba (con alguna modificación). Dicho cuestionario hace referencia a una serie de habilidades de exploración clínica por apartados (un total de 93 habilidades), y a una serie de procedimientos clínicos (total 47 procedimientos). La respuesta depende de una graduación: "me lo han explicado", "lo he visto hacer", "lo he hecho", "soy capaz de hacerlo". La muestra ha sido de 66 alumnos pertenecientes al quinto curso de la licenciatura.

Sobre la base de las respuestas obtenidas entre los alumnos, las diez habilidades de exploración clínica que más frecuentemente los alumnos han realizado y/o consideran que están capacitados son:

- Tomar el pulso arterial periférico (98\%)

- Hacer una anamnesis completa centrada en el enfermo (98\%)

- Reconocer una paliez (97\%)

- Localizar los focos de auscultación cardiaca (97\%)

- Auscultar los ruidos cardiacos anormales (97\%)

- Tomar la opresión arterial (95\%)

- Reconocer una ictericia (95\%)

- Reconocer unas sibilancias (94\%)

- Valorar unos edemas (92\%)

- Reconocer una cianosis (91\%)

Paralelamente se obtuvieron los procedimientos clínicos que los alumnos consideran que son capaces de realizar y que, señalando sólo los cinco mejores, fueron:

- Tomar la presión arterial (98 \%)

- Interpretar un electrocardiograma (94\%)

- Interpretar la radiografía simple de tórax (93\%)

- Interpretar la radiografía simple de abdomen $(83 \%)$

- Interpretar los resultados de los exámenes analíticos básicos de sangre (82\%)

Con una metodología similar es posible detectar las áreas de mejora como aquellas en las que el alumno considera que se encuentra peor formado y peor capacitado para realizarlas. Pero al mismo tiempo estas experiencias son una muestra de que sólo definiendo las competencias clínicas que el alumno debe tener, y diseñando un método para evaluarlas, estaremos en disposición de garantizar una formación nuclear sobre los aspectos más relevantes de la formación médica. 